\title{
A Aporia do Espaço em Godbout*
}

Eunice Dutra Galéry ${ }^{1}$

\begin{abstract}
RESUMO: Buscou-se mostrar, através desse estudo, pela utilização da psicanálise, como se organiza o espaço em Godbout e como a aporia constituída por este espaço é pretensamente resolvida por uma espécie de auto-anulação representada pela imobilidade e pelo desejo de retorno ao útero.
\end{abstract}

A questão do espaço revela-se de primordial importância em Godbout, refletindo, de certa forma, o impasse em que se encontra a população do Québec, ilhada num continente de fala inglesa.

Acuados em sua província, os cidadãos do Québec, fracionados entre o desejo de manter/adquirir uma identidade, e a fascinação que sobre eles exerce o "american way of life", parecem andar em círculos, não se atrevendo a assumir uma posição definida.

O estudo que se segue constitui uma tentativa de mostrar, através de uma aproximação psicanalítica, como a obra de Godbout reflete uma aporia, sentindo-se as personagens impotentes para sair e sufocadas ao ficar; a solução tentada é, no final das contas, uma não-solução, pois representa uma espécie de fuga aniquiiladora, o abrigo no ventre materno.

Como preliminar para a melhor compreensão do que se vai dizer, segue-se o resumo das obras que constituem o "corpus" no qual se baseia $o$ artigo.

* Recebido para publicação em abril de 1988.

1. Professora de Língua e Literatura Francesas na Faculdade de Letras da UFMG.

CALIGRAMA - Belo Horizonte, 1:133-141 - outubro/1988 
1. L'AQUARIUM - A ação do romance se passa num país africano não identificado e conta a vida de "cooperantes" estrangeiros que ali vivem, às vésperas de uma revolução. Após a morte de um dos habitantes da "Casa Occidentale", edifício onde moram os cooperantes, os outros moradores são mostrados em seu quotidiano, divididos entre o desejo de sair do país, de se protegerem dos efeitos da revolução que se aproxima, e o sentimento de culpa advindo de terem deixado morrer aquele que não nomeiam, a quem se referem sempre como IL ou LUI. O herói do romance, que assume a maior parte da narrativa, se apaixona por Andrée, antiga amante de LUI, que chegara à "Casa" após a sua morte nas areias movediças. Apoderando-se do dinheiro deixado pelo morto, o narrador escapa, em companhia de Andrée. O final do romance deixa o leitor em dúvida quanto ao destino dos demais moradores da "Casa", fechados no apartamento do narrador, à mercê, pois, dos revolucionáricios que lutam em toda a cidade.

2. LE COUTEAU SUR LA TABLE - Segundo o romancista, este romance é a retomada das personagens de L'AQUARIUM, vivendo, agora, na América. O narrador se apaixona por uma milionária canadense-inglesa, Patrícia, quando prestava serviço militar no oeste do Canadá. Desertando, foge com a amante para Montréal, tentando uma vida em comum. Patrícia torna-se amante de um canadense-inglês e o narrador, por sua vez, liga-se a uma canadense-francesa, Madeleine, a quem convida para partilhar o apartamento onde ele e Patrícia já viviam. No final de algum tempo, Patricia se cansa e parte. Madeleine, grávida, morre num acidente de moto. O narrador rouba a farmácia onde trabalhava, preparando uma longa viagem pelos Estados Unidos e México. Após essa viagem, ele retorna a Montréal, indo novamente viver com Patrícia, desta vez no "Eastview Castle", casa dos pais dela, tentando refazer uma vida em comum. Essa segunda tentativa, porém, parece fadada ao fracasso, e o narrador sonha com uma nova evasão.

3. SALUT GALARNEAU! Pela primeira vez, em Godbout, o narrador tem um nome: François Galarneau. Oriundo de uma família de três irmãos, na qual o pai e a mãe não se entendiam, e que era sustentada pelo avô paterno, François, após a morte do pai, viaja para Lévis, onde se casa com Louise, que o faz crer que espera um filho. Descobrindo o engodo de que fora vítima, já que 
a mulher não estava grávida, François retorna a Montréal, onde se estabelece como vendedor de cachorros-quentes, num "stand" à beira da estrada. Saindo uma noite com seu irmão mais velho, Jacques, ele conhece Marise Doucet, com quem passa a viver maritalmente. Marise, no entanto, mostra certa inclinação por Jacques e acabará por trair François. A partir desse momento, o narrador se encerra em sua casa, em volta da qual manda construir um muro sem portas, para se isolar do mundo. A narrativa termina deixando o leitor na dúvida sobre o destino do narrador: permanecerá ele encerrado em sua casa, ou pulará o muro, para recomeçar a viver?

4. LES TÉTES À PAPINEAU - Em Montréal nasce uma criança de duas cabeças. A convivência entre elas se torna cada vez mais difícil, quando chegam à idade adulta. Um médico célebre se propõe a operá-las, "amalgamando-as". Após muito hesitar, elas decidem se deixar operar. Internadas no hospital, as "cabeças" escrevem seu diário, contando, ao mesmo tempo, toda sua história. A operação tem um resultado inesperado, já que o indivíduo que sai da mesa de operação é incapaz de falar ou de compreender o francês, língua materna das cabeças.

$\mathrm{O}$ espaço em Godbout lembra, por sua indecisão, o que, em linguagem jurídica, se convencionou chamar a sala dos passos perdidos e que serve para designar uma espécie de antecâmara, um não-lugar onde se cruzam as pessoas que têm alguma relação com a justiça e "marque le seuil d'une étrange région (...), du lieu ou non-lieu où se perdent existence et identité". ${ }^{2}$

Antecâmara do tribunal, lugar de espera, de angústia $\epsilon$, ao mesmo tempo, de esperança, essa sala pode ser considerada, também, como sala dos pas perdus - daqueles que ainda não estão perdidos - pela transformação do substantivo pas no advérbio homógrafo.

Sala dos pas perdus, porque ainda não foram submetidos a julgamento: resta-lhes, pois, a débil esperança da absolvição.

Esperança de poder se livrar do castigo, esperança de ficar quite com a justiça, ou esperança amarga e paradoxal de receber, enfim, o castigo exigido por sua própria consciência culpada.

Paradoxal esperança pelo avesso, que lembra o episódio descrito por Lacan, quando fala a respeito de Tzara, para quem o aprisio-

2. MARTIN, 1966. p. 198. 
namento e o envio ao campo de concentração, durante a última Guerra. Mundial, tornam-se alívio para a angústia da espera. ${ }^{3}$

As personagens de Godbout parecem, no entanto, comprazer-se nessa espera: elas permanecem correndo em círculo nessa metafórica sala dos pas perdus, da qual não ousam sair, porque só há duas saídas possíveis: uma, arriscar-se no espaço aberto exterior; outra, encarar o julgamento - julgamento de um foro interior, muito mais severo do que qualquer juri externo.

Elas preferem permanecer nessa sala, fingindo ser apenas testemunhas e não, criminosos à espera do julgamento; testemunhas de suas próprias vidas que elas se esquecem de viver ou que não se atrevem a viver.

Elas brincam de fingir que são invisíveis, o que lhes permite estar em toda parte e em lugar nenhum - como o centro de seu universo ou, em última instância, como Deus. Deus, demiurgo, senhor de vida e de morte de suas personagens.

Sala dos passos perdidos, finalmente, porque seus passos não levam a lugar nenhum - pretendendo (e nesse verbo inclui-se o sentido de fingir, como o de querer), avançar, elas andam em marcha a ré, vão ao encontro de seu próprio passado, andando para trás, em cima de um tapete rolante.

Que se chamem Charles François Papineau, que se chamem François Galarneau, ou que não tenham nomes, pouco importa: sua trajetória é a mesma: o retorno às origens.

Isso acontece em L'Aquarium, onde o narrador volta para a América, depois de sua estada na África, objeto de sua narrativatestemunho; ou, para tombar, em Le Conteau sur la table, em algum lugar no oeste canadense e, finalmente, em Montréal. O mesmo que acontece a François Galarneau, que parte de Montréal e acaba voltando para lá, acontece também a Charles-François que, partindo de um hospital em Montréal, termina em um hospital, na mesma cidade.

Aos grandes círculos que constituem as idas e voltas, sucedem os pequenos movimentos de vaivém. Assim, se em L'Aquarium, o narrador consegue chegar até à Äfrica, antes de voltar, em Le Couteau sur la table ele passa pelos Estados Unidos e pelo México; em Salut Galarneau!, ele chega somente até Lévis e, em Les Têtes

3. Cf. LACAN, 1966. p. 315. 
à Papineau, apenas faz menção aos lugares que as Têtes teriam visitado: o essencial de sua história passa-se em Montréal e arredores.

O espaço se reduz, em Godbout, de um romance ao outro, 4 assim como em cada romance.

Essa redução do espaço configura a linha fantasmática do retorno às origens, o fantasma de mergulhar novamente no útero materno.

$\mathrm{O}$ efeito de sur-place, ligado à sensação de estar sem rumo, perdido em lugar estranho, sensação que as personagens de Godbout exprimem freqüentemente, faz também pensar no Unheimlich freudiano: ao mesmo tempo apelo e repulsa, o inquietante familiarestranho invade a escritura de Godbout e, ligado ao fantasma de retorno ao útero, cria uma espécie de sintoma, essa paralisia-agitada, representada pelo sur-place.

As personagens evitam a paralisia total, mortal, através de movimentos que só têm como finalidade evitar a morte, parecendo reproduzir a situação que Lacan descreve em Le séminaire sur la lettre volée, onde o ministro, ao esconder a carta roubada, repete o processo anteriormente usado pela rainda, e é

“. . captivé aussitôt par une relation duelle où nous retrouvons tous les caractères du leurre mimétique de l'animal qui fait le mort, et, pris au piège de la situation typiquement imaginaire: de voir qu'on ne le voit pas, méconnaître la situation réelle où il est vu de ne pas voir". 5

Dessa forma, as personagens godboutianas mimetizam o movimento, correndo sem sair do lugar, já que sair do lugar representa um perigo tão mortal quanto a paralisia: deixar o ventre materno, enfrentar a vida, com todas as possibilidades de errar pelos caminhos que ela comporta, eis o que elas não se atravem a encarar.

Seguir em frente é sinônimo de ir ao encontro da morte, metáfora amplamente desenvolvida em L'Aquarium, quando o narra-

4. Essa afirmação pode ser verificada também nos outros romances de Godbout: em D'Amour P.Q. os fatos se passam em Montréal; em L'Isle au Dragon, numa ilha do São Lourenço; e Une Histoire américaine numa cela de prisão, na Califórnia.

5. LACAN, 1966. p. 30-1. 
dor nota que os moradores da Casa tinham "tant et tant marché ce jour-là" (A-28), para presenciar a morte de Lui.

Ās personagens de Godbout, é necessário um território que as tranqüilize e as proteja do mundo externo e ameaçador; é-lhes necessário esse cercle immobile (A-73), onde se encontram à vontade. No entanto, elas não aguientam ficar presas por muito tempo nesse círculo: daí os movimentos desvairados visando à liberação e que as leva a se perderem cada vez que ousam sair.

Monsignore, uma das personagens de L'Aquarium, "s'égara dans le marché" (A-16), ele e seu assistente Pauline "vont, ouvrent une porte, reviennent; un ballet américain des pas perdus" (A-42); o narrador de L'Aquarium "hésite toujours devant vingt sentiers" (A-111), enquanto o de Le Couteau sur la table se encontra em um "tournant de (sa) vie" (CT-35) ; a sensação do Unheimtich é perfeitamente descrita no momento em que Patrícia rompe seu relacionamento com o narrador, que assim descreve sua reação:

"Je me surpris à marcher dans Montréal qui se cachait sous des néons papillotants virevoltants sous des affiches étourdissantes (...) Dans certains quartiers, je me disais: je suis à New York sûrement dans la sixième avenue, car voici la cinquantedeuxième rue $(\ldots)$. Je marchais. Plus loin je me surpris à dire: comme Paris a changé: les maisons sont comme des gosses ont grandi les rues sont plus larges les pierres moins grises" $(\mathrm{A}-28 / 29) .6$

Aos olhos do narrador, tomado de vertigem diante do rompimento, a cidade arqui-conhecida torna-se estranha, estrangeira, enquanto seus passos incertos não levam a parte alguma: rodando a esmo, ele só consegue chegar - como sempre - ao lugar de onde saíra, seu apartamento.

O mesmo passeio errático dentro da escuridão da noite vai-se repetir quando da morte de Madeleine:

"Quand je m'y décidai je ne parvins pas à descendre vers le centre commercial, à chaque carrefour j'empruntais la mauvaise route, insensiblement j'enfilais une ruelle après l'autre pour déboucher tout à coup dans la rue des Coulombes - après autant de détours que de mensonges (CT-143)".7

6. GODBOUT, 1962. p. 28-9.

7. GODBOUT, 1965. p. 143 . 
Voltas e mentiras que o levam, justamente, ao lugar onde sempre quer chegar, à casa-origem, aqui a casa dos pais de Madeleine.

Interessante se torna comparar esse passeio descrito por Godbout com o que Freud descreve no seu estudo sobre $O$ Estranho:

"Em certa tarde de verão caminhava eu pelas ruas desertas de uma cidade provinciana na Itália, quando me encontrei num quarteirão sobre cujo caráter não podia ficar em dúvida por muito tempo. Só se viam mulheres pintadas nas janelas das pequenas casas, e apressei-me a deixar a estreita rua na esquina seguinte. Mas, depois de haver vagado algum tempo sem perguntar o meu caminho, encontrei-me subitamente de volta à mesma rua, onde a minha presença agora começava a despertar a atenção. Afastei-me apressadamente uma vez mais, apenas para chegar, por meio de outro détour, à mesma rua pela terceira vez. Agora, no entanto, sobreveio-me uma sensação que só posso descrever como estranha, e alegrei-me bastante por encontrar-me de volta à piazza que deixara pouco antes, sem quaisquer outras viagens de descoberta." 8

Esse mesmo alívio de encontrar-se de volta depois de uma série de détours, é exatamente a sensação que descreve François Galarneau, quando descobre a traição de Jacques e Marise. François comenta que "quand (il) a quitté Jacques et Marise, (il) ne savai (t) vraiment plus où aller" (SC-117. Grifo do autor). Entretanto, não saber aonde ir, leva-o finalmente à procura de Arthur, seu outro irmão, que, por "coincidência", tinha comprado de novo a casa paterna (SG-120). Não deixa de ser curiosa a observação do narrador, ao empregar um possessivo plural, corrigindo um possessivo singular que, no final das contas, era o correto: "Je suis arrivé chez lui - chez nous - à la fin de la soirée" (SG-121. Grifo meu) .

A repetição desse mesmo movimento simbólico de retorno às origens, à casa paterna - melhor vale dizer, à casa materna, pois, no fundo, é a mãe que o narrador procura sempre - acontece cada vez que ele se vê na contingência de tomar uma decisão. Dessa forma, não é surpresa nenhuma, ao ler Les Têtes à Papineau, ver-se que as Têtes retornam à casa de seus pais, antes de se decidirem a se fazer amalgamar pelo dr. Northridge.

Casa paterna, símbolo do ventre materno, a sala dos passos perdidos parece se enquadrar perfeitamente na descrição barthesiana da antecâmara:

8. FREUD, 1980. v. 17, p. 296 . 
“...espace éternel de toutes les sujections, puisque c'est là qu'on attend. L'Anti-Chambre $(\ldots)$ est un milieu de transmission: elle participe à la fois de l'intérieur et de l'extérieur, du Pouvoir et de L'Evènement, du caché et de l'étendu; saisie entre le monde, lieu d'action, et la Chambre, lieu du silence, l'Anti-Chambre est l'espace du langage." 9

Essa sala dos passos perdidos é, pois, o lugar a partir do qual se pode falar, porque não sendo aí possível a ação, é somente pela palavra que as personagens se definem, têm a impressão de existir.

Não é, portanto, sem uma razão profunda que, em Salut Galarneau!, François sonha em "remplacer le mur de ciment par un mur de papier, de mots, de cahiers" (SG-137).

$\mathbf{E}$ essa personagem, esse narrador, cujo olhar e cujo próprio cenário vêm de outra parte, reconstrói as pegadas de outro tempo e de outro espaço, das várias personagens que intervêm na composição do romance, criando uma ilusão de realidade que o scriptor desvenda de uma vez por todas: sob uma imitação de diário íntimo, um ser feito de tinta lhe serve de porta-voz. Esse desvendamento se faz em muitas ocasiões, como se o scriptor quisesse avisar o leitor a respeito da fabulação; essa atitude leva, num jogo de espelho, à denegação, fazendo lembrar a história dos dois judeus que se encontram na estação, contada por Freud.

Falo de denegação porque, nesse limbo que se constitui a sala dos passos perdidos, só há lugar para as palavras. No entanto, as próprias palavras são, de certa forma, um calabouço onde as personagens, especialmente os narradores, se encontram fechadas.

Dessa prisão - e o último romance de Godbout vem confirmar a dedução, pois o narrador de Une Histoire américaine escreve dentro de uma cela - as pessoas sonham sempre em se evadir. Evasão através das palavras, mas evasão, já que, na sala dos passos perdidos, os, narradores vêem perfeitamente que, se de um lado aí se encontram em segurança, ao abrigo do mundo, por outro, nesse lugar eles estão condenados a refazer sempre a mesma cena que, como coloquei antes, se passou em outro tempo e em outro espaço.

Nessa antecâmara,

9. BARTHES, 1963. p. 10. 
“... appel à la fois de la vie et de la mort, de la vie-mort, de la perte $(\ldots)$ (qui) insiste sur l'angoisse que provoque chez le sujet cet appel vers la perte, vers vivre-mourir, auquel le sujet réagit en se perdant dans la paralysie," 10

marcar passo - e passo perdido - torna-se insuportável ao fim de algum tempo e, assim sendo, os heróis procuram escapar: mas, nem bem chegam à soleira de uma das portas possíveis, o medo "la grande chienne de peur, l'énorme chiasse, le trou devant soi" (CT-57), sufoca-os e eles fazem meia-volta.

RESUMĒ: On a essayé, dans cette étude, par l'utilisation de la psychanalyse, de montrer comment s'organise l'espace chez Godbout et comment l'aporie constituée par cet espace est faussement résolue par une sorte d'auto-anéantissement représenté par l'immobilité et par le désir de retour à l'utérus.

\section{REFERÊNCIAS BIBLIOGRĀFICAAS}

BARTHES, R. Sur Racine. Paris, Seuil, 1963.

FREUD, S. Edição standard brasileira das obras psicológicas completas de

Sigmund Freud. Trad. Jayme Salomão. Rio de Janeiro, Imago, 1980, 24 v. GODBOUT, Jacques. L'Aquarium. Paris, Seuil, 1962.

D'Amour P. Q. Paris, Seuil,Montréal, Hurtubise, 1972.

- Le Couteau sur la table. Paris, Seuil, 1965.

- Une histoire américaine. Paris, Seuil, 1986.

- L'Isle au Dragon. Paris, Seuil, 1976.

- Salut Galarneau!. Paris, Seuil, 1967.

. Les Têtes à Papineau. Paris, Seuil, 1981.

LACAN, J. Ecrits. Paris, Seuil, 1966.

MARTIN, J-P. «La Condensation». Poétique, Paris, (26), 1966.

10. MARTIN, 1966. p. 198. 